based on the program at San Francisco General Hospital. Legal, ethical, and emotional issues following accidental exposures are also discussed. Copies of HIV and the Healthcare W orker are available by calling the Glaxo Video Library at 1-800-824-2896.

\section{New CDC Recommendations Call for Voluntary Testing of Hospital Patients}

CDC new recommendations call for routine assessment of patients' HIV risk and the offering of voluntary testing to patients at risk. Decisions to offer routine HIV counseling and testing of patients in acutecare hospitals may be based on the HIV seroprevalence in the patient population. Hospitals can use either the HIV seroprevalence rate or the AIDS diagnosis rate ([annual number of AIDS patients/annual number of discharges] x 1,000). Those hospitals and healthcare providers with an HIV seroprevalence rate of $>0.1 \%$ or an AIDS diagnosis rate $>1 / 1,000$ discharges should strongly consider offering HIV testing to patients ages 15 to 54 years.

These guidelines also stress voluntary testing with informed consent, confidentiality, appropriate pre- and posttest counseling, provision of optimum medical care even if patient declines testing, and referral for appropriate therapeutic and preventive services. HIV testing programs should not be used as a substitute for universal precautions and other infection control techniques, the guidelines state.
The CDC has also indicated that state and local health departments can provide assistance to hospitals in determining their AIDS diagnosis rate, training staff responsible for HIV testing and counseling, and providing prevention services for uninfected patients at high risk for HIV infection.

FROM: CDC. Recommendations for HIV testing services for inpatients and outpatients in acutecare hospitals. MMWR. RR-2:42:1-6:1993.

\section{Kimberly-Clark Offers Toll-Free Hotline on Key Infection Control Issues}

Kimberly-Clark's Helpline, originally a service to answer specific questions on OSHA's Bloodborne Pathogen Rule, has expanded to include information and resources on other healthcare worker risk issues. Registered nurses at Kimberly-Clark's Helpline answer questions on key infection control issues, such as tuberculosis, medical waste, recycling, and bloodborne pathogens. A common question from callers is how to select a protective garment that is an appropriate barrier and also comfortable to wear, in order to comply with OSHA standards. Audio and video training tapes are also available, as well as key OSHA documents related to the Final Bloodborne Pathogen Rule. Call KimberlyClark's Partners in QuaiityTM helpline at $1-800-\mathrm{KC}$ HELPS (1-800-524-3577). 


\section{The Third Annual Meeting of}

Errarar

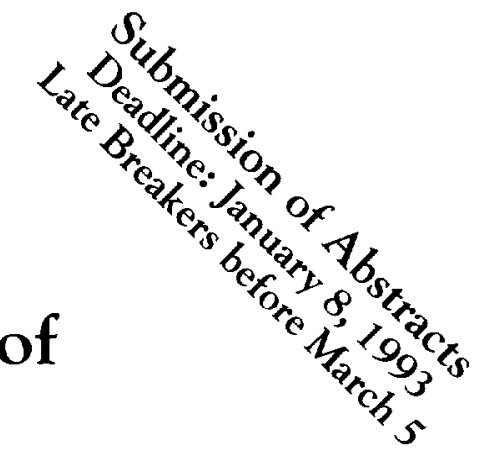

\section{The Society for}

\section{Hospital Epidemiology}

of America

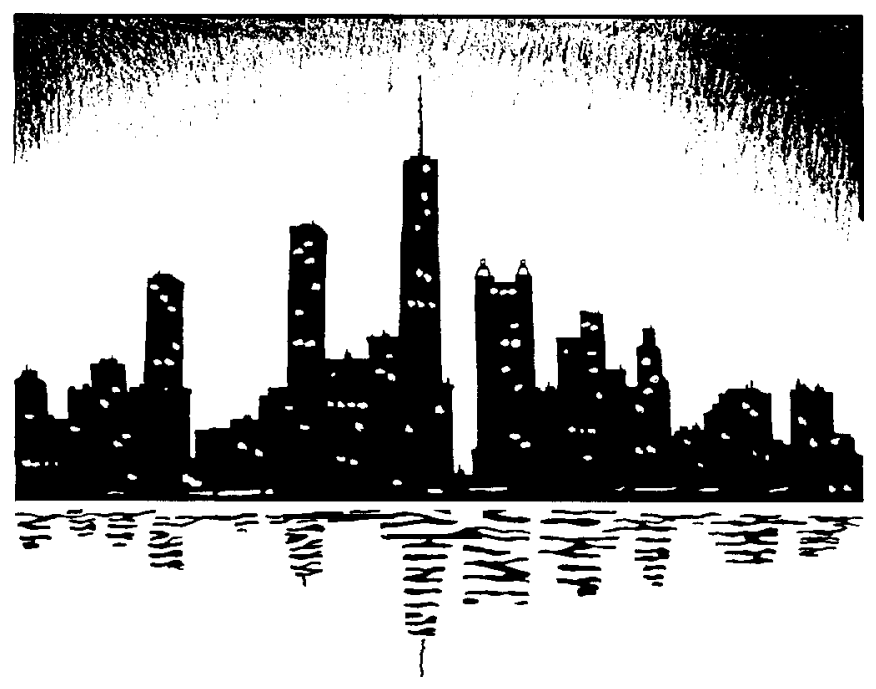

\section{April 18-20, 1993 \\ The Palmer House Hotel, Chicago, Illinois}

\section{5 hours of Category 1/AMA Credit}

For Preliminary Program and Registration Information, please contact SHEA at 609-845-1720 or fax 609-853-04 11

University of Illinois College of Medicne is accredited by the Accreditation Council for CME to sponsor continuing medical education for physicians. University of Illinois College of Medicine designates this continuing medical education activity for 15 credit hours in Category 1 of Physicians Recognition A ward of the A merican Medical Association. 